\title{
Assessment of the liability risk in the Nordic port
}

\section{Elena Istochka*, Katsiaryna Ivanova*, Mohammad Shahriari and Mats Lindgren}

Department of Product and Production Development, Chalmers University of Technology,

SE-412 96 Gothenburg, Sweden

E-mail: elena_0801@yahoo.com

E-mail: katerivan@gmail.com

E-mail: mohammad.shahriari@chalmers.se

E-mail: mats@stoop.nu

*Corresponding authors

\begin{abstract}
This study was conducted for insurance purposes at the oil refinery of Company $\mathrm{X}$ in one of the Nordic countries whose facilities such as depot and terminal lie in the port. The facilities of Company $\mathrm{X}$ in the port are surrounded by the facilities of other companies. In case of an accident caused by Company $\mathrm{X}$, the oil tanks and buildings of other companies would be damaged and there would be potential liability claims from their side. Insurance risk assessment is a well-developed approach for insurance of a company's own property. It is not normally used for liability risks. This study suggests methodology for determination of liability insurance values. Based on the obtained results and calculations of replacement values, the worst case scenario for Company $\mathrm{X}$ in the port was chosen and recommendations were made regarding the liability risk.
\end{abstract}

Keywords: liability; insurance; risk assessment.

Reference to this paper should be made as follows: Istochka, E., Ivanova, K., Shahriari, M. and Lindgren, M. (2013) 'Assessment of the liability risk in the Nordic port', Int. J. Liability and Scientific Enquiry, Vol. 6, Nos. 1/2/3, pp.64-78.

Biographical notes: Elena Istochka holds an MSc in Complex Adaptive Systems from Chalmers University of Technology, Gothenburg, Sweden.

Katsiaryna Ivanova holds an MSc in Product Development from Chalmers University of Technology, Gothenburg, Sweden.

Mohammad Shahriari holds a Docent/PhD from Department of Product and Production Development, Division of Production System, Chalmers University of Technology, Gothenburg, Sweden.

Mats Lindgren is a Risk Manager at Company X.

This paper is a revised and expanded version of a paper entitled 'Liability risk assessment in Skarvik Port' presented at International Symposium on Occupational Safety and Hygiene, Guimarães, 10-11 February 2012. 


\section{Introduction}

In a case of accidents in oil and chemical industries, very large damages can be caused both to the company where the accident happens and to the other companies whose facilities lie close to the place of the accident.

Our research is related to a Company X, which is surrounded by other companies' (hereinafter 'neighbour-companies') facilities in the port, all of them storing liquefied petroleum gas, gasoline, diesel, heating oil etc. This means that if there is an accident at Company X's facilities, it can lead to the destruction of property and business interruption of neighbour-companies, which means a potential for damages claims.

Due to that reason we were motivated to suggest a methodology for determination of liability risks in oil and chemical industries and to determine liability risk for Company X.

For accomplishing the aim of this study a lot of accidents in the oil and chemical industries with biggest damage to other companies were considered and the information about business interruption claims in those cases was used. The next stage was modelling the most common accident scenarios, in order to determine the potential damages from such accidents to the neighbour companies of Company X. As a result, the worst case scenario for Company $\mathrm{X}$ in the port was chosen and recommendations were made regarding the liability risk. The paper consists of aim of the study, theoretical background, methodology, modelling description, findings, calculation of total replacement costs description and conclusions.

\section{Aim of the study}

The aim of the study is to suggest methodology for determination of liability risks in oil and chemical industries and to determine liability risk for Company $\mathrm{X}$ including the total limit (maximum insurance value that can be paid). The aim is also to make recommendations to Company $\mathrm{X}$ regarding:

a insurance against legal liability for damages to other parties

b risk mitigation options given the liability risks assessment.

\section{Theoretical background}

Conducting a literature survey, several types of fires and explosions were proposed as the most common ones that can lead to such damage. Vapour cloud explosion (VCE) can be defined as "an explosion caused by the instantaneous burning of vapour cloud formed in air due to release of flammable chemical" (Nolan, 1996). Usually if there is loss of containment in a refinery, vapour or gas fuel is released. In order for a VCE to occur there must be a large release of flammable material in the atmosphere, a subsequent dispersion phase, and after some delay, an ignition of the vapour cloud (CCPS, 1994). Due to the explosion overpressure, which propagates outwards from the explosion site, a pressure wave is produced (Gowl, 2003). Not all of the released material participates in a VCE. The lowest percentage of the substance in air (the lowest concentration) that will burn when an ignition source is present is known as the lower flammable limit (LFL). If 
the concentration is lower than LFL, the mixture is too 'lean' to burn. Upper flammability limit (UFL) of a vapour or gas is the highest percentage of the substance in air (the highest concentration) that will produce a burn when an ignition source is present. For concentration higher than UFL, the mixture is too 'rich' or 'overcarbonated', to burn (Kent, 2007).

A VCE can be classified as either confined or unconfined. A confined explosion is one that occurs inside a process vessel or a building. In this type of explosion even a slow combustion process will generate overpressure (Bjerketvedt et al., 1993). An explosion for which there is no venting or heat loss is known as fully confined explosion. This type of explosion generates high overpressure in the range of a factor eight times the starting overpressure. If there is region with obstacles, known as a congested region, there will be increased turbulences because the flow is obstructed by objects. Explosions in open areas are known as unconfined explosions. If it is truly unconfined, for an unobstructed gas cloud ignited by a weak ignition source, only a small overpressure while burning, a so called flash fire, will be produced (Bjerketvedt et al., 1993).

A vapour cloud generally has three regions (CCPS, 1994). Near the point of the release is the rich region, at the edge of the cloud is the lean region and between these two is the flammable region. In order to have an extensive overpressure a sufficient amount of the cloud must be within the flammable range of the material. Other factors that influence the vapour cloud in each region are: type and amount of material released; pressure and time of release; size of release opening; wind, humidity, and other environmental effects (CCPS, 1996).

Another very common type of explosion is boiling liquid expanding vapour explosion (BLEVE). If the boiling point of a liquid is above ambient temperature and the liquid is heated before release by an external heat source to a temperature above its boiling point - it can cause a BLEVE. BLEVE is defined as 'an explosion resulting from a failure of a vessel containing a liquid at a temperature significantly above its boiling point at normal atmospheric pressure (CCPS, 1994). A liquid does not have to be flammable to cause BLEVE, which is the main difference between this type of explosion and VCE (see above).

Non-flammable liquid BLEVE can cause two effects: overpressure due to the expansion of the vapour in the container with flashing of the liquid, as well as fragmentation of the container. Since liquids within containers are a combination of liquid and vapour, before container's rupture the liquid phase is in equilibrium with the vapour phase. When it comes to a rupture of the container the vapour is vented and the liquid's surrounding pressure drops sharply. In case of a higher than boiling liquid temperature but lower than the superheat temperature, instantaneous boiling may occur throughout the bulk of the liquid. This will in turn cause formation of large number of vapour bubbles in the liquid. This means that within a very short time a large fraction of the liquid will vaporise. In such cases the energy for the blast and fragment generation is mainly due to the expansion of the vapour in the space above the liquid. On the other hand, if the temperature of the liquid is higher than the superheat limit temperature, very high energy will be liberated. This will cause high blast pressure and generation of fragments with high initial velocities, which can be thrown long distances.

Factors such as: external fire, mechanical impact, corrosion, excessive internal pressure and metallurgical failures can influence the failure of a container. BLEVEs are usually associated with release of flammable liquids from vessels as a result of external fires, which means that BLEVE's effects are determined by the condition of the contents 
in the container and of its walls at the moment of the containers failure. If a container with flammable liquid is heated its metal is heated and loses mechanical strength. The heat is transferred to the liquid and liquid's temperature rises. When the boiling point is reached vapour bubbles are formed at the active sites that occur at interface with solids, including vessels walls. This type of BLEVE is accompanied by a fireball. A cloud of almost pure vapour and mist is formed due to the rapid vaporisation, expansion and loss of containment. After the vapour is ignited it starts to burn at the surface where it's mixed with air. The combustion propagates to the centre of the cloud and a fireball is obtained.

An accident such as that, which includes a fireball, is followed by a powerful heat radiation - heat flux. Parameters that affect the radiation effects are: the diameter of the fireball as a function of time, the maximum diameter of the fireball, the height of the centre of the fireball above its ignition position as a function of time (after lift-off), the surface - emissive power of the fireball and the duration of combustion (CCPS, 1996).

The consequences of the radiation are determined by the distance of the fireball to targets and atmospheric transmissivity.

A pool fire can be defined as "a turbulent diffusion fire burning above a horizontal pool vaporising flammable material under conditions where the flammable material has zero or very low initial momentum" (Cowley and Johnson, 1991). The most characteristic thing for this type of fire is that there is a heat transfer back from the fire to the pool. This means that the rate of evaporation is influenced, or even controlled, by that feedback, which makes fire size and some other characteristics to depend on it as well.

Liquid fuels can burn either in an open storage container or on the ground or in the form of a spill. For a given amount of fuel, spill with a large surface area will have a high heat release rate (HRR) for a short duration, and spills with a smaller surface area will have a lower HRR for a longer duration (Tewarson, 1995). If a flammable liquid is spilled it may form a pool of any shape and thickness and once it's ignited the fire will spread rapidly over the spilled area.

The shape (form) of the fuel material together with the fuel composition (chemistry) influences the burning duration. Pool fires can have different diameters depending on: release mode, release quantity, burning rate etc. There can be confined pool fire e.g. in a case of release into containment dikes, and unconfined e.g. in a case of releases from LPG or gasoline road tanks.

Dense gas can be defined as 'gas which has a higher specific weight than the surrounding ambient air' (Britter and Griffiths, 1982). Most flammable gases are denser-than-air, as a consequence the flammable dense gas cloud will normally remain in the lower part of the atmosphere and it will largely spread in the lateral direction and it will not disperse as fast as a light gas. Due to that reason, a release of a dense gas has a higher potential of forming larger fuel air clouds than a release of a light gas (Bjerketvedt et al., 1993).

A large number of materials can form dense gas clouds. Within the refinery industry many products are vapours under atmospheric pressure. However, these products are commonly stored or transported as liquids, maintained in that phase at, or near, their saturation temperature at atmospheric pressure by refrigeration and insulation, or at ambient temperature by pressurisation (Yellow Book, 2005). If somehow containment like that is lost, most or all of the liquid will vaporise.

For risk assessment purposes there are three primary ways of release: rapid-in a case of catastrophic failure of a pressure vessel; continuous-if the release is through a small hole in the vapour space of a pressure vessel; and combination of the two mentioned 
above-if a low boiling point liquid from a refrigerated vessel is released onto land. In that case, assuming that the pool spread is limited, there will be an initial rapid boil - off, followed by a more steady evolution of vapour.

Based on those fires and explosions, six scenarios were selected for modelling. For that aim a software program called EFFECTS was used.

EFFECTS is used by many industrial companies, governments and research institutions around the world. The latest version of the software by the time of this study is EFFECTS 8. It is used to perform safety analysis for the petrochemical industry. EFFECTS 8 offers calculation models for accidents with storage and transportation of chemicals (TNO, 2011).

A large variety of chemicals can be handled by this the software, since it has a database containing toxic, flammable and thermodynamic properties (TNO, 2011). However there is also a possibility for the user to extend the database with chemicals that are needed for some specific work.

The calculations and physical effects of any accident scenario with toxic and/or flammable chemicals made with EFFECTS are given in tables, graphs and on geographical maps. Also, valuable information for hazard identification, safety analysis, quantitative risk analysis (QRA) and emergency planning is provided through the contours of effects, such as overpressure, heat radiation and consequences like lethality and structural damage.

In many industries, including oil and petrochemical, a lot of techniques for risk assessment are used. Mainly, when there is a potential hazardous event the event tree analysis (ETA) is used as a technique for identifying the consequences of it. This technique provides possibility to predict the frequency of all potential accident scenarios in a case of such an event. The event that triggers hazardous situation is known as initiating event. ETA is an inductive technique because it examines all possible responses that can be cause from the initiating event. Each branch of the tree structure represents success, failure or partial failure of the events related to the initiating event.

It can be seen that when a tree like this is constructed several steps need to be included. First of all the initial event that triggers unwanted consequences needs to be identified as well as the consequences resulting from it. Next thing that need to be done is to determine the frequency of the accidental event as well as the accident event and the probabilities of the branches in the tree. At the end, the probabilities (frequencies) for the outcomes (consequences) are calculated and the results are presented.

\section{Methodology}

The study was divided into three parts.

- literature study

- modelling of potential accidents at Company X facilities

- assessment of potential liability claims from other companies

The objective of the literature study was to find the accidents in the oil and chemical industries with the biggest damages to other companies and extract information about business interruption claims in these cases. Thereafter modelling of such accident scenarios was done to determine potential damages from such accidents to the neighbour- 
companies. The final part of the study assess the potential business interruption damages caused by Company $\mathrm{X}$ to the neighbour-companies in case of serious accidents such as fire, explosion or uncontrolled release caused by Company X.

\section{$5 \quad$ Modelling}

After literature search and careful discussion of probable accidents with Company X's risk manager a preliminary list of scenarios was compiled. For some of them generic ETA was used. Some information for ETA was taken from Vilchez et al. (2009). Scenario in this thesis is defined as a sequence of events leading to an accident.

Separate ETA were compiled for Pool fire and VCE.

As for pool fire, given quick and effective fire response it will not have consequences, but otherwise it will lead to secondary fires.

The final list of scenarios was modelled using a software developed by the Netherlands Organisation for Applied Scientific Research (TNO), called EFFECTS 8.1. Methods of calculation of physical effects ('Yellow Book') and EFFECTS manual were used to calculate necessary input values as follows. For modelling of all of the scenarios the background map was georeferenced, meaning that pixel coordinates were translated to real world coordinates using a utility included in EFFECTS. The other parameters for modelling were calculated as follows:

Distance from release (Xd); Downwind horizontal coordinate (Xd) from the point of study (i.e., the point where the concentration is to be calculated) to the release point, the outer limit of calculations (TNO, 2010).

Threshold overpressure is the overpressure value (in $\mathrm{mBar}$ ) for which we want to calculate the distance from the centre mass position where it is reached (output value). It is also the threshold value to be used when calculating the output contour plot of all the positions where this overpressure is reached (TNO, 2010). This is an arbitrary value, which is plotted on the map, but it has been decided not to plot it in one of the damage contours.

The explosion damage contours are:

- $\quad$ total destruction $(>83 \mathrm{kPa})$

- $\quad$ heavy damage (35-83 $\mathrm{kPa})$

- Moderate damage (17-35 kPa)

- $\quad$ Minor damage (3.5-17 kPa)

The damage is thus dependent upon the overpressure (TNO, 2010). The thermal radiation damage contours are depicted in Table 1.

It is said in the source that "the available information on the effects of heat radiation does not differentiate between various types of structures. Therefore a single set of damage criteria [is] used for heat radiation", and heat radiation levels are depicted in Table 2 (Dreher, 1999).

Damage to structures (empirical) at $\mathrm{Xd}$ is the damage suffered by a structure if it was situated at the point of study (TNO, 2010). Nineteen different situations can be found: 
- the supporting structure of a round storage tank has collapsed (100 kPa)

- brickstone walls $(20-30 \mathrm{~cm})$ have collapsed (50 $\mathrm{kPa})$

- displacement of a cylindrical storage tank, failure of connecting pipes (50-100 kPa)

- loaded train carriages turned over $(50 \mathrm{kPa})$

- collapse of a pipe-bridge (40-55 $\mathrm{kPa})$

- displacement of a pipe-bridge, rupture of piping (35-40 kPa)

- damage to a fractioning column $(35-80 \mathrm{kPa})$

- plating of cars and trucks pressed inwards $(35 \mathrm{kPa})$

- breakage of wooden telephone poles (35 kPa)

- cladding of light industry building ripped-off (30 $\mathrm{kPa})$

- collapse of steel frames and displacement of foundation (20 kPa)

- industrial steel self-framing structure collapsed (20-30 kPa)

- cracking in empty oil-storage tanks (20-30 kPa)

- slight deformation of a pipe-bridge (20-30 kPa)

- large trees have fallen down (20-40 $\mathrm{kPa})$

- walls made of concrete blocks have collapsed (15-20)

- minor damage to steel frames $(8-10 \mathrm{kPa})$

- connections between steel or aluminium ondulated plates have failed (7-14 kPa)

- the roof of a storage tank has collapsed $(7 \mathrm{kPa})$.

\section{Findings}

\subsection{Scenario 1: VCE}

Tank 130 overfills with gasoline for 15 minutes, while flow is $800 \mathrm{~m}^{3} / \mathrm{h}$. It is assumed that $10 \%$ of leaked mass turns into vapour, similar to Buncefield accident (BMIIB, 2008).

$$
V_{\text {leaked }}=200 \mathrm{~m}^{3} ; \text { Vgasoline turned to vapour }=20 \mathrm{~m}^{3} ; m_{\text {gasoline vapour }}=\rho \cdot v=719.7 \mathrm{~kg} / \mathrm{m} 3 .
$$

\subsection{Scenario 2: BLEVE at LPG storage}

The scenario is the following consequence of events. Pipe rupture during transfer of LPG causes leak from a gas (i.e., propane) tank, propane ignites and heats another tank. This eventually triggers BLEVE. Scenario 2 can also be triggered by the consequences of Scenario 1. Thermal radiation damage levels are taken from Figure 3. It is said in the source that "the available information on the effects of heat radiation does not 
differentiate between various types of structures. Therefore a single set of damage criteria

[is] used for heat radiation" (Dreher, 1999).

This result is considered to be overly conservative because of the short heat duration. This shows the need for more precise heat flux values for process industries.

\subsection{Scenario 3: leak from a hole in a gasoline tank}

In this scenario tank starts to leak, detection time $15 \mathrm{~min}$. Estimated fraction of product to turn into vapour is $10 \%$, similar to Buncefield accident (BMIIB, 2008). The scenario was modelled for Preem tank 137. First, the mass of released liquid is calculated with the help of EFFECTS model 'Liquid Release'. It calculates the mass escaped from the $80 \%$ full tank.

\subsection{Scenario 4: LPG leak, dense gas explosion}

In this scenario propane leaks from the bottom of the tank which leads to explosion.

The cause of leak could be, e.g., human error during maintenance (hot work or cold work, i.e., dismantling of flanges without proper isolation and depressurisation, and different ignition source in the vicinity), or mechanical impact, e.g., collision, or pump seal failure.

\subsection{Scenario 5: rupture of propane vessel}

In this scenario, propane vessel ruptures from metal fatigue of flanges

\subsection{Scenario 6: diesel pool fire}

Diesel pool fire consequences are considered lighter then the consequences of gasoline pool fire (Schnepp, 2009). So given the fact that diesel is not in EFFECTS database it was decided to model gasoline pool fire instead and consider it a worst/case scenario. The scenario modelled is a fire in one of the storage tanks. The outer circle shows the edge of the second heat radiation contour for all possible wind directions.

\subsection{Calculation of total replacement costs for worst-case scenarios (including domino-effects)}

EFFECTS 8.1 does not have an option for calculating replacement costs. In order to determine the worst case scenario, manual calculations were conducted. Total replacement costs for the tanks, product inside of the tanks, clearance of the debris, fire fighting and some others for the neighbouring companies of Company $\mathrm{X}$ are calculated.

Secondary damage can happen if there is escalation, spreading of the fire etc., i.e., fire in a damaged tank gets to another tank and it also catches fire. It is reasonably assumed that there is a risk to catch fire for the tanks that are about 1 diameter away from the last tank that is damaged in EFFECTS calculations, according to Company X's judgement.

Since the only replacement values available for this study were given for Company $\mathrm{X}$ groups of tanks, the replacement value for one tank was calculated by dividing that value to the number of tanks in the group. Because of the fact that each tank has different 
volume, the replacement value per unit of volume was obtained by dividing the replacement value per tank by the volume of the tank.

The following types of roofs can be found on Company X's tanks: dome, floating roof and dome with floating roof inside.

Given that the replacement value per unit of volume was calculated for all the tanks, the average value was calculated for the tanks with the same type of roof and that value was considered to be the replacement value per unit of volume for that type of tank. The procedure was repeated for the other tanks with same type of roof. At the end, from all the values that were obtained the average value was calculated used as a replacement value per unit of volume. That replacement value multiplied with the volume of the tanks that were destroyed gave the replacement value for those tanks.

Information about other companies' tanks, their locations and contents was taken from Environmental Protection Division of County Administration for Västra Götaland county (Miljöskyddsenheten). Using this methodology Scenario 1 for the tank 137 was found to be the worst-case scenario.

\section{Conclusions}

Methodology to determine liability risk was developed and tested using EFFECTS 8.1. The suggested methodology includes the study of previous accidents, what-if analysis, ETA, modelling of the most probable scenarios in EFFECST 8.1 and manual consideration of domino effects. Some parameters for the modelling, like fraction of flammable cloud confined, were also considered manually. Using the developed methodology the worst-case scenario was chosen.

It can be reasonably assumed that Scenario 1 can lead to BLEVE in LPG storage (Scenario 2). But since it is impossible to establish the replacement values for BLEVE consequences - Scenario 1 remains the worst-case in terms of liability risk. The similar methodology can be used for the assessment of liability risk in chemical and oil industries as well as to determine the insurance value of a company's own property.

Limitations for this study primarily concern the limitations of the software used (it does not have a capability to handle multi-component mixtures etc). Business interruption claims is a matter most often solved privately and thus it was hard to find open references about it. The objective of this study was to assess specifically property and business interruption damage, the possible effect of the accidents to people and environment and also the effect of the accidents that are not Company X's fault (i.e., force majeure) has been excluded from it.

The developed methodology can be applied in oil and chemical industries for determination of the consequences of fire and explosion - both in terms of destruction of own property and liability risk. As for academic implications - the research shows the use of combination of existing theory for real-life tasks. It can be expanded and made more precise, i.e., in terms of heat flux values for process industries. The results suggest that to get a more precise liability risk value for a company, surrounded by the facilities of other companies, a lot of external data is needed - i.e., the description of the facilities of the other companies, the contents of their tanks and valuation of the tanks, product inside of them and machinery used at the facility.

There was a number of uncertainties in this study. Fraction of flammable cloud confined was calculated manually according to the Yellow Book's methodology which 
might be overly conservative. Another way of doing the calculation of total mass in the cloud would be through EFFECTS models 'Pool evaporation' and 'Dense gas dispersion: Explosive mass'. However EFFECTS does not have a capability to handle multicomponent mixtures.

\section{References}

Bjerketvedt, D., Bakke, J.R. and van Wingerden, K. (1993) Gas Explosion Handbook, Christian Michelsen Research AS.

Britter, R.E. and Griffiths, R.F. (1982) 'The role of dense gases in the assessment of industrial hazards', Journal of Hazardous Materials, Vol. 6, No. 1, pp.3-12.

BMIIB (2008) 'The final report of the Major Incident Investigation Board', Vol. 1, p.7.

CCPS (1994) Guidelines for Evaluating the Characteristics of Vapour Cloud Explosions, Flash Fires And Bleves, Center for Chemical Process Safety, Preservation Press.

CCPS (1996) Guidelines for Use of Vapor Cloud Dispersion Models, Center for Chemical Process Safety, 2nd edition, Wiley-AIChE.

Cowley, L.T. and Johnson A.D. (1991) 'Blast and fire engineering project for topside structures, fill oil and gas fires: characteristics and impacts, blast and fire engineering project for top-side structures', work package no. FL1.

Dreher, L. (1999) 'VRJ loss prevention tool for petrochemical plants', Institution of Engineers (Australia) Risk Engineering Society Conference: Risk'99 Back to the Future.

Gowl, D.A. (2003) 'Understanding explosions', Center for Chemical Process Safety of the American Institute of Chemical Engineering.

Kent, J.A. (2007) Kent and Riegel's Handbook of Industrial Chemistry and Biotechnology, 11th ed., Vol. 1, p.103, Library of Congress Control Number: 2005938809, Springer Science+Business Media, New York, USA.

Nolan, D.P. (1996) Handbook of Fire and Explosion Protection Engineering Principles for Oil, Gas, Chemical, and Related Facilities, p.49, Noyes Publications, Burlington, MA, USA.

Tewarson, A. (1995) 'Estimating burning characteristics of liquid pool fire, heat release rate, burning duration and flame height', SFPE Handbook of Fire Protection Engineering, 2a edicion, NFPA, Chapter 3.

TNO (2010) TNO Safety software EFFECTS Version 8, User and manual.

Schnepp, R. (2009) Hazardous Materials: Awareness And Operations, International Association of Fire Chiefs, National Fire Protection Association, p.24, Jones \& Bartlett Publishers.

TNO (2011) 'The coloured books - yellow, green, purple, red', [online] http://www.tno.nl (accessed 06 July 2011).

Yellow Book (2005) Methods for the Calculation of Physical Effects Due to Release of Hazardous Materials (Liquids and Gases), Third edition, Second revised print, Commission for the Prevention of Disasters caused by Hazardous Materials, Netherlands. 


\section{Appendix}

Table 1 Thermal radiation damage contours

\begin{tabular}{lc}
\hline Heat flux, $\mathrm{kW} / \mathrm{m} 2$ & Damage level \\
\hline $470 \%$ & $10 \%$ \\
$800 \%$ & $30 \%$ \\
$1,260 \%$ & $50 \%$ \\
$1,800 \%$ & $80 \%$ \\
$2,300 \%$ & $100 \%$ \\
\hline
\end{tabular}

Source: Dreher (1999)

Table 2 Heat radiation levels

\begin{tabular}{ll}
\hline Heat flux & \multicolumn{1}{c}{ Observed effect } \\
\hline $35-37,5 \mathrm{~kW} \cdot \mathrm{m}-2$ & $\begin{array}{l}\text { Sufficient to cause damage to process equipment. Cellulosic material will } \\
\text { pilot ignite within one minute's exposure. }\end{array}$ \\
$23-25 \mathrm{~kW} \cdot \mathrm{m}-2$ & $\begin{array}{l}\text { Spontaneous ignition of wood after long exposure. Unprotected steel will } \\
\text { reach thermal stress temperatures which can cause failures. Pressure vessel } \\
\text { needs to be relieved or failure will occur. }\end{array}$ \\
$12.6 \mathrm{~kW} \cdot \mathrm{m}-2$ & $\begin{array}{l}\text { Thin steel with insulation on the side away from the fire may reach a } \\
\text { thermal stress level high enough to cause structural failure. Minimum } \\
\text { energy required for piloted ignition of wood, melting of plastic tubing. }\end{array}$ \\
\hline
\end{tabular}

Source: Dreher (1999)

Figure 1 ETA for liquid spill

\begin{tabular}{|l|l|l|l|l|l|}
\hline $\begin{array}{l}\text { Initiating } \\
\text { event }\end{array}$ & $\begin{array}{l}\text { Quick detection } \\
\text { and effective } \\
\text { action }\end{array}$ & $\begin{array}{l}\text { Immidiate } \\
\text { ignition }\end{array}$ & $\begin{array}{l}\text { Delayed } \\
\text { ignition }\end{array}$ & $\begin{array}{l}\text { Flame front } \\
\text { acceleration* }\end{array}$ & Final scenario \\
\hline
\end{tabular}

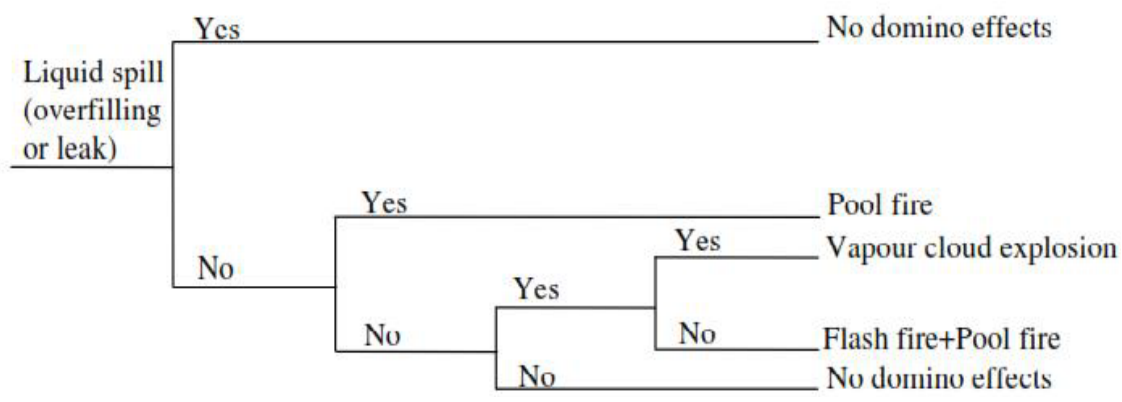

Note: *Depends on confinement level of the explosion, turbulence, etc. 
Figure 2 ETA for VCE

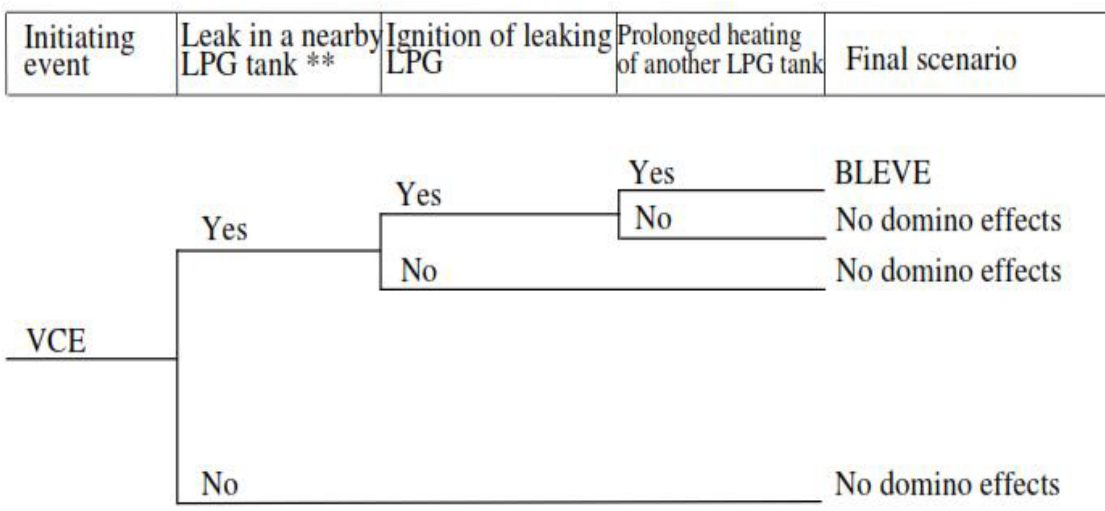

Note: $* *$ Due to the effect of the explosion

Figure 3 Modelling results for Scenario 1 at tank 130 with highlighted borders of Company X borders (see online version for colours)
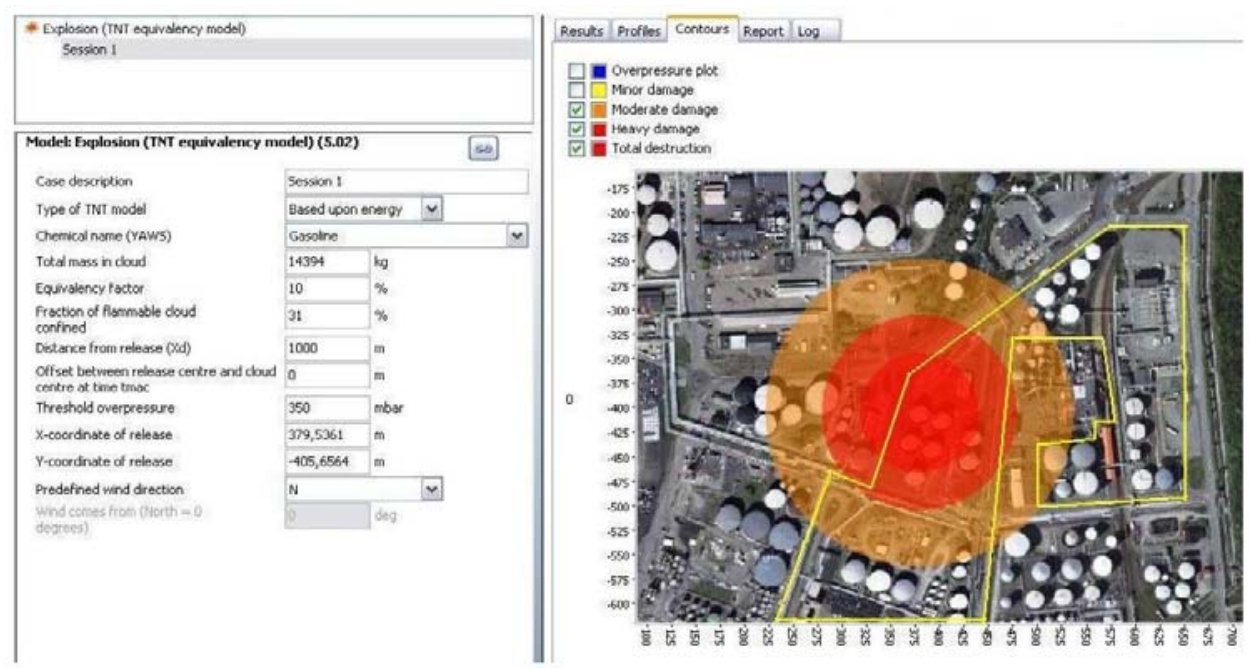
Figure 4 Scenario 2 (see online version for colours)
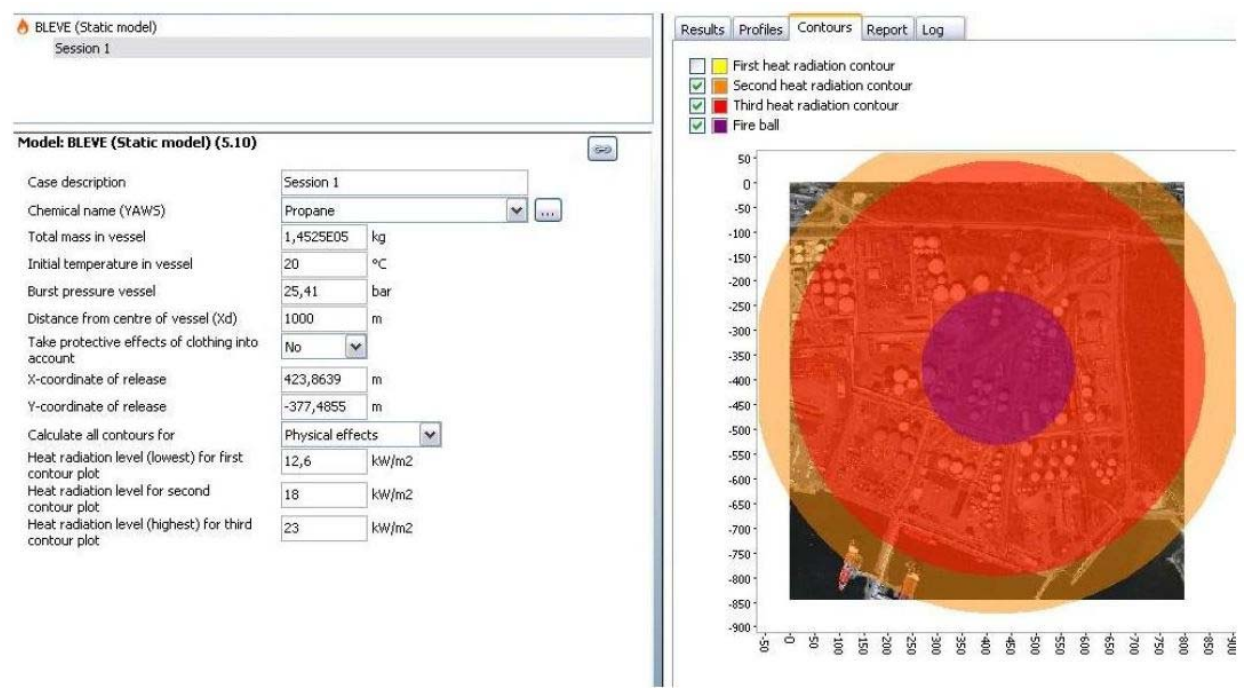

Figure 5 Scenario 3 (see online version for colours)

\begin{tabular}{|c|c|c|c|}
\hline \multicolumn{3}{|c|}{ Model: Explosion (INT equivalency model) (5.02) } & $\infty$ \\
\hline \multirow{4}{*}{$\begin{array}{l}\text { Coses descriptian } \\
\text { Type of TwI model } \\
\text { Chenical name (YAWS) } \\
\text { Total mass in doud }\end{array}$} & \multicolumn{3}{|l|}{ Session 1} \\
\hline & \multicolumn{3}{|c|}{ Oased upon energy v } \\
\hline & \multicolumn{2}{|c|}{ Gasolne } & $\sim \ldots$ \\
\hline & 1109,7 & $\mathrm{~kg}$ & \\
\hline \multirow{3}{*}{$\begin{array}{l}\text { Equirdency factor } \\
\text { proxtion of flismmoble clout } \\
\text { corfined }\end{array}$} & 10 & $\%$ & \\
\hline & 100 & $\%$ & \\
\hline & 1000 & $\mathrm{~m}$ & \\
\hline \multirow{2}{*}{$\begin{array}{l}\text { Offset between release centre and doud } \\
\text { contre o } \alpha \text { bimo tmac } \\
\text { Thresthold overpessure }\end{array}$} & 0 & $\mathrm{~m}$ & \\
\hline & 350 & mbar & \\
\hline 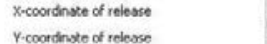 & $\frac{5+2,9002}{.258,5287}$ & $m$ & \\
\hline \multirow{2}{*}{$\begin{array}{l}\text { Predefined wind drection } \\
\text { Wind cones fion flocth = }\end{array}$} & $\mathrm{N}$ & $v$ & \\
\hline & 0 & des & \\
\hline
\end{tabular}

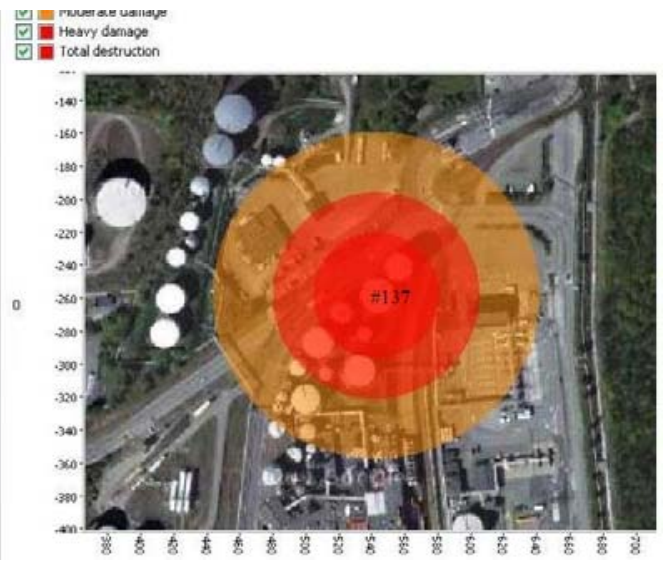


Figure 8 Scenario 6 (see online version for colours)

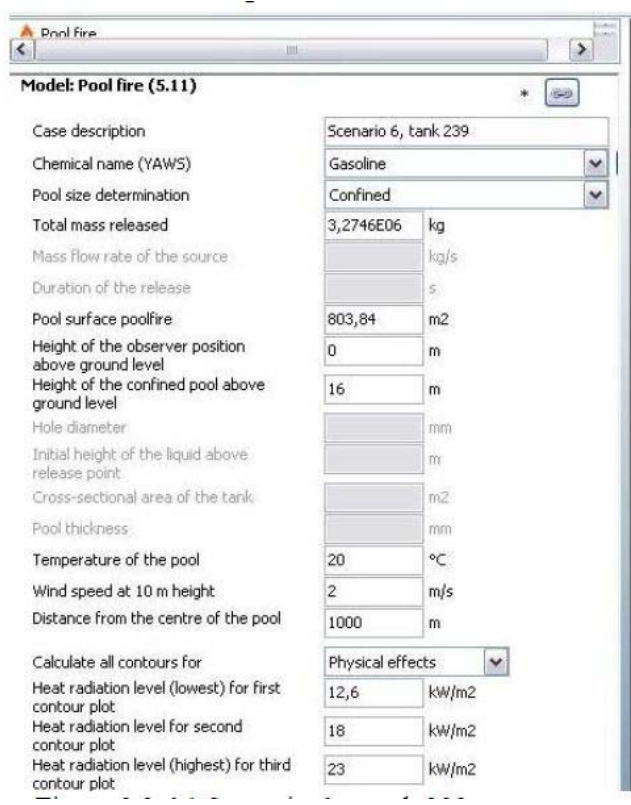

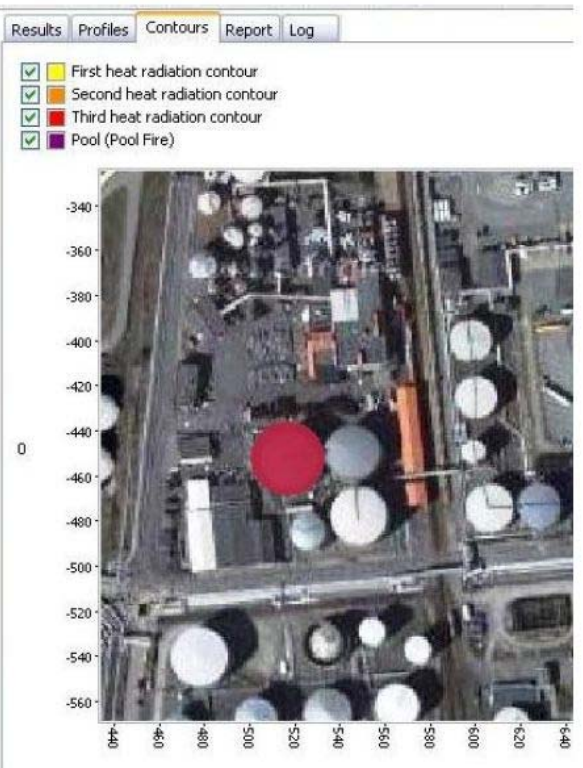

